\title{
Airway Management in the Critically III Patient
}

\author{
Bhupinder Natt ${ }^{1} \cdot$ Jarrod Mosier ${ }^{1,2}$ (D)
}

Accepted: 23 March 2021 / Published online: 19 April 2021

(C) The Author(s), under exclusive licence to Springer Science+Business Media, LLC, part of Springer Nature 2021

\begin{abstract}
Purpose of Review This paper will evaluate the recent literature and best practices in airway management in critically ill patients. Recent Findings Cardiac arrest remains a common complication of intubation in these high-risk patients. Patients with desaturation or peri-intubation hypotension are at high risk of cardiac arrest, and each of these complications have been reported in up to half of all intubations in critically ill patient populations.

Summary There have been significant advances in preoxygenation and devices available for performing laryngoscopy and rescue oxygenation. However, the risk of cardiovascular collapse remains concerningly high with few studies to guide therapeutic maneuvers to reduce this risk.
\end{abstract}

Keywords Intubation $\cdot$ Critically ill $\cdot$ Preoxygenation $\cdot$ Cardiovascular collapse $\cdot$ Desaturation $\cdot$ Hemodynamics

\section{Introduction}

Airway management has always been central to critical care. It is noted, for instance, in ancient Egyptian hieroglyphs, Hippocratic writings, a tale of Alexander the Great opening the trachea of an asphyxiating soldier, and reports of George Washington's death from a peritonsillar abscess. Accessing what Leonardo da Vinci referred to as the arteria aspera has been a source of danger, marvel, and intense study for as long as physicians have cared for the ill. Almost seven decades ago during a polio epidemic, modern critical care emerged when the Danish anesthesiologist Bjørn Ibsen saved lives by performing tracheostomies on polio patients with respiratory failure. Today, a new global pandemic is again forcing critical care medicine to struggle with whom to intubate with acute respiratory failure and how to best perform a procedure that carries a $2-4 \%$ cardiac arrest rate $[1 \bullet$. Intubation practices for treating acute critically ill patients outside of the operating

This article is part of the Topical Collection on Airway Management

Jarrod Mosier

jmosier@aemrc.arizona.edu

1 Division of Pulmonary, Allergy, Critical Care, and Sleep, Department of Medicine, University of Arizona College of Medicine, Tucson, AZ, USA

2 Department of Emergency Medicine, University of Arizona College of Medicine, 1501 N Campbell Ave, AHSL 4171D, PO Box 245057, Tucson, AZ 85724-5057, USA room (OR) are largely based on OR techniques. For example, rapid sequence induction and intubation, developed to prevent aspiration, was adopted to facilitate laryngoscopy and intubation success in the emergency department (ED) and then in the intensive care unit (ICU) — now singularly referred to as rapid sequence intubation (RSI). Preoxygenation to avoid the need for mask ventilation as well as to prevent aspiration evolved to avoid desaturation, the most common and dangerous complication outside of the OR, despite critically ill patients being mostly unfasted and at a high risk of aspiration. In addition, supraglottic airway devices designed to facilitate operative cases without requiring an endotracheal tube have become invaluable reoxygenation tools in critically ill patients with missed attempts and desaturation. Yet, despite adoption and evolution of OR practices to the ED and ICU, the first guidelines specific for critically ill patients were not published until 2018 [2], and recognition of deranged physiology that increases the risk of complications despite the presence or absence of procedural difficulty with laryngoscopy-i.e., the physiologically difficult airway - is only recently becoming more clear [3]. It is starting to be recognized that focusing on airway strategies that take into account physiology and attempt to reduce the risk of rapid desaturation or cardiovascular collapse plays an important role in these patients. Focusing on the most expedient laryngoscopy possible and attempting to rescue the decompensation after the intubation increases the risk in this high-risk population. In this paper, we will review advances in airway management in the critically ill patient, focusing on physiologic optimization, preparation, 
and devices used to prevent and manage the difficult airway. A summary of our recommendations can be found in Table 1 .

\section{Search Strategy}

We conducted a Medline search using PubMed with the following search terms, from 2000-present: intubation [tiab] [MeSH Terms], AND (sequentially): ((critically ill [tiab]) OR (critical illness [MeSH Terms]) OR (emergency [tiab]) OR (emergency services [MeSH Terms]) OR (preoxygenation [tiab]) OR (mask ventilation [tiab]) OR (rapid sequence intubation [tiab]) OR (awake intubation [tiab]) OR (hypotension [tiab]) OR (shock [tiab]) OR (shock [MeSH Terms]) OR (respiratory insufficiency [MeSH Terms]) OR (respiratory failure [tiab]) OR (sepsis [tiab]) OR (cricoid pressure [tiab]) OR (bougie [tiab]) OR (tracheal introducer [tiab]) OR (direct laryngoscopy [tiab]) OR (video laryngoscopy [tiab]) OR (endoscope [tiab]) OR (supraglottic airway [tiab]) OR (laryngeal mask airway [tiab]) OR (extraglottic airway [tiab]) OR (cricothyrotomy [tiab]) OR (front of neck access [tiab]) OR (critically ill [tiab]) AND ((intubation[MeSH Terms]))) AND ((“2000/01/01”[Date - Create] : “3000”[Date - Create])).
Studies on neonates or pediatric patients $\leq 18$ years and nonEnglish language reports were excluded. Abstracts were reviewed for relevance, and references from each selected article were reviewed for pertinent articles. A (nonexhaustive) list of important articles as determined by the authors for establishing or verifying important concepts or changing practice are detailed in Table 2.

\section{Preoxygenation}

Preoxygenation was introduced at a time when the biggest risk from intubation was aspiration during induction for high-risk surgeries, such as bowel obstructions or cesarean sections [ $[1 \bullet$, 4-6]. The idea was to have patients breathe $100 \%$ oxygen prior to induction to avoid gastric insufflation with mask ventilation. This practice developed prior to the invention of pulse oximetry, and it has been assimilated into airway management in all clinical settings. The intent has evolved to avoid desaturation more so than passive regurgitation and aspiration with mask ventilation [1•]. In critically ill patients, desaturation is a very common and serious threat to patient safety $[1 \cdot]$, which carries a fourfold increase in the adjusted

Table 1 Authors' recommendations for airway management in critically ill patients

\begin{tabular}{|c|c|c|}
\hline Topic & Recommendation & Comments \\
\hline Positioning & $\begin{array}{l}\text { 1. Ramped plus "sniffing" (lower cervical spine is flexed, the upper } \\
\text { cervical spine is extended, and the ear is leveled with the sternal } \\
\text { notch) positions for all patients } \\
\text { 2. Gastric decompression when faced with a high risk of aspiration }\end{array}$ & $\begin{array}{l}\text { 1. If supine position planned, recommend preoxygenating in upright } \\
\text { position to optimize oxygen delivery. } \\
\text { 2. Gastric ultrasound can help stratify risk. }\end{array}$ \\
\hline Preoxygenation & $\begin{array}{l}\text { 1. Flush flow* rate oxygen should be the default preoxygenation } \\
\text { method. } \\
\text { 2. In patients with higher risk of desaturation, preoxygenation should be } \\
\text { performed with HFNO or NIPPV. } \\
\text { 3. For those most severely hypoxemic, where RSI is still planned, } \\
\text { preoxygenation should be performed with NIPPV. } \\
\text { 4. For those most severe where an awake intubation is planned, HFNO } \\
\text { during the procedure should be used. } \\
\text { 5. Consider mask ventilation between induction and laryngoscopy } \\
\text { when feasible. } \\
\text { 6. Apneic oxygenation should be used when feasible. }\end{array}$ & $\begin{array}{l}\text { 1. In patients with acute hypoxemic respiratory failure, a } \mathrm{PaO} 2 \text { to } \mathrm{FiO} 2 \\
\text { ratio (or } \mathrm{SpO} 2 \text { to } \mathrm{FiO} 2 \text { equivalent) can be helpful to stratify } \\
\text { preoxygenation. } \\
\text { 2. } \mathrm{PaO} 2 \text { to } \mathrm{FiO} 2 \text { ratio }>200 \text { on } \mathrm{NRB} \text { at flush rate = proceed with } \mathrm{RSI} \\
\text { 3. } \mathrm{PaO} 2 \text { to } \mathrm{FiO} 2 \text { ratio }<100-200 \text { on } \mathrm{NRB} \text { at flush rate = escalate to } \\
\mathrm{NIPPV} \text { or } \mathrm{HFNO} \\
\text { 4. } \mathrm{PaO} 2 \text { to } \mathrm{FiO} 2 \text { ratio }<100 \text { on NIPPV or } \mathrm{HFNO}=\text { consider awake } \\
\text { intubation }\end{array}$ \\
\hline Hemodynamics & $\begin{array}{l}\text { 1. Hemodynamics should be assessed prior to intubation. } \\
\text { 2. Optimization should be informed by the underlying physiology on } \\
\text { assessment. }\end{array}$ & $\begin{array}{l}\text { 1. We recommend fluid resuscitation where appropriate. } \\
\text { 2. We recommend norepinephrine infusion as the default vasopressor } \\
\text { or choice. } \\
\text { 3. We recommend an RV-guided resuscitation when necessary. } \\
\text { 4. Some patients are too unstable for RSI and need a staged awake } \\
\text { intubation and gradual transition to positive pressure ventilation. }\end{array}$ \\
\hline Laryngoscopy & $\begin{array}{l}\text { 1. We recommend VL as the default laryngoscope when available. } \\
\text { 2. Consider routine use of a bougie when using traditional Macintosh } \\
\text { geometry laryngoscopy (either DL or VL). } \\
\text { 3. A second-generation supraglottic airway device should be used when } \\
\text { available if rescue oxygenation cannot be accomplished with } \\
\text { bag-valve-mask ventilation. }\end{array}$ & $\begin{array}{l}\text { 1. There are many advantages and very little downside to routine use of } \\
\text { VL. In addition, there are many cost-effective options for VL that are } \\
\text { widely available. }\end{array}$ \\
\hline
\end{tabular}

$R S I$, rapid sequence intubation; $N I P P V$, noninvasive positive pressure ventilation; $H F N O$, high-flow nasal oxygen; $N R B$, nonrebreathing mask; $D L$, direct laryngoscopy; $V L$, video laryngoscopy

*Flush flow rate oxygen refers to using a standard nonrebreathing reservoir mask and opening the valve from the wall regulator all the way, which generally provides between 50 and 801 of oxygen depending on the hospital's oxygen system pressurization 
odds of cardiac arrest compared to patients without desaturation [7]. The strategy for preoxygenation of a patient with severe pneumonia or acute respiratory distress syndrome (ARDS) should be different from a patient who requires intubation but does not present with significant respiratory pathology. Preoxygenation can be very challenging, especially when patients require intubation for acute hypoxemic respiratory failure after failing noninvasive strategies, such as noninvasive positive pressure ventilation (NIPPV) or high flow nasal oxygen (HFNO) $[8,9]$. Patients that fail NIPPV and require intubation have, at best, modest increases in the partial pressure of arterial oxygen $(\mathrm{PaO} 2)$ when preoxygenated with the traditional practice of breathing $100 \%$ oxygen for $4 \min$ [10]. Furthermore, extending the preoxygenation time has only been marginally effective at further increasing the $\mathrm{PaO} 2$, and the $\mathrm{PaO} 2$ of many patients worsened [11].

We have learned a great deal about preoxygenation over the last decade. Safe apnea provided by preoxygenation is improved with maximal denitrogenation, an adequate functional residual capacity (FRC), and minimizing shunting $[12 \bullet, 13]$. Essentially, you need three things to achieve safe apnea: (1) a reservoir to draw upon during apnea (i.e., the FRC), (2) maximum oxygen in that reservoir (i.e., denitrogenation), and (3) availability of that reservoir to resaturate hemoglobin (i.e., minimal shunt). In patients without airspace disease, traditional preoxygenation usually accomplishes the first goal, while FRC and shunt are not usually concerns. However, the more severe a patient's airspace disease and hypoxemia are (e.g., ARDS), the more each of those three requirements become distinct challenges of their own that need to be addressed.

Denitrogenation of the FRC is impaired by diluting the oxygen source with ambient room air $[14,15]$. The higher the patient's work of breathing and the greater the peak inspiratory flow rate, the more room air is entrained and the effective fraction of inspired oxygen ( $\mathrm{FiO} 2)$ lowers - reducing the ability to denitrogenate the FRC. This can be evaluated by assessing the fraction of expired oxygen $(\mathrm{FeO} 2)$ by measuring the end-tidal oxygen (ETO2). Once the leak is introduced in or around the oxygen source and is contaminated by ambient room air, the $\mathrm{FeO} 2$ drops by about half [10, 15-17]. The same is true of bag-valve-masks that do not have a one-way exhalation valve [14]. Despite a seal, room air is entrained and the $\mathrm{FeO} 2$ drops. Overcoming this leak by adding a nasal cannula is only mildly effective [15], yet if high enough flows are used (15 lpm), a goal ETO2 can be reached more rapidly than BVM alone [18]. However, overcoming room air entrainment by increasing the flow rate to "flush rate," where the wall regulator valve is completely open, can effectively restore adequate denitrogenation and ETO2 that approaches those achieved with a tight seal [19].

Removing the source of oxygen prior to the patient being fully apneic after induction leads to a rapid renitrogenation with any spontaneous breaths that occurred before the onset of apnea [20]. Continuous insufflation of oxygen in the nasopharynx during apnea can attenuate this renitrogenation and prolong safe apnea time; however, clinical data are mixed [21-28] and this is less likely to be effective in the presence of a large shunt fraction $[12 \cdot, 29]$. Preoxygenation in the upright position has a potential to increase the FRC by recruiting the lung bases [30], as well as preoxygenation with NIPPV $[31-33,34 \cdot 0]$ and, potentially, mask ventilation in the latent period [35].

In patients with hypoxemic respiratory failure (e.g., ARDS), the large shunt fraction is extremely problematic to safe apnea [12•]. Not only is the FRC smaller, but also the shunt renders that deoxygenated reservoir is less forgiving of inadequacies (e.g., removing oxygen and room air entrainment) and relinquishes the reservoir only partially available to resaturate hemoglobin [12•]. Thus, in these patients, more aggressive preoxygenation modalities are necessary for there to be any chance of safe apnea during RSI.

While these more aggressive forms of preoxygenation come from HFNO and NIPPV, the literature can be challenging to interpret regarding which one to use and when. Preoxygenation with NIPPV in hypoxemic patients has shown benefits with fewer patients desaturating compared to bagvalve-mask preoxygenation [36]. HFNO has the potential benefit of remaining in place for apneic oxygenation - particularly useful for the difficult airway-yet the required trial to definitively answer this question would be unethical in critically ill patients. Vourc'h et al. reported that the rate of difficult intubation was (statistically) similar, although clinically significant, with $1.6 \%$ difficult intubations in the HFNO group and $7.1 \%$ in the facemask group [37]. Most studies evaluate success rates rather than apnea duration, and despite significant heterogeneity, studies have generally shown HFNO to be at least as good as facemask preoxygenation $[21,22,26,32,34 \bullet$, $38-41]$. For preventing desaturation, there is also substantial heterogeneity in the patient population selected and the severity of hypoxemia between studies. In general, HFNO prevents desaturation, prolongs safe apnea time, and limits the depth of desaturation compared to facemask preoxygenation, but not NIPPV [21, 24, 26, 34••, 37-43]. Miguel-Montanes et al. reported an incidence of $14 \%$ in a nonrebreather group, $2 \%$ in the HFNO group, with HFNO being an independent predictor of preventing desaturation $<80 \%$ (aOR $0.140 .01 ; 0.90)$ in a multivariable regression model [42]. In the patients with the most severe hypoxemia undergoing RSI, HFNO may not be as useful [37], where NIPPV appears to provide the best preoxygenation $[24,32,34 \cdot \bullet]$. However, HFNO can remain in place for apneic oxygenation and may provide some benefit. In a recent study, the incidence of desaturation was higher for HFNO (23\%), compared to $2.5 \%$ for NIPPV; however, none of the HFNO patients desaturated to $<70 \%$ compared to $13 \%$ of the NIPPV patients [38]. 
Table 2 Important studies over the last 10 years

\begin{tabular}{|c|c|c|c|}
\hline Year & Author(s) & Journal & Importance \\
\hline 2010 & Jaber S. et al. & Intensive Care Med 2010; 36: 248-255 & $\begin{array}{l}\text { This study found that implementation of a bundle aimed at improving safety } \\
\text { reduced complications by more than } 10 \% \text {. }\end{array}$ \\
\hline 2011 & Aziz M. et al. & Anesthesiology 2011; 114: 34-41 & $\begin{array}{l}\text { This observational study showed that GlideScope use resulted in a very high } \\
\text { first-attempt success as both the primary device (98\%) and after failed direct } \\
\text { laryngoscopy }(96 \%) \text {. }\end{array}$ \\
\hline 2011 & Marsch S. et al. & Crit Care 2011; 15: R199 & $\begin{array}{l}\text { This study compared rocuronium and succinylcholine in the ICU and showed } \\
\text { no difference in desaturation incidence, depth or duration, intubating } \\
\text { conditions, or success rates. }\end{array}$ \\
\hline 2012 & Heffner A. et al. & J Crit Care 2012; 27: 417.e419-413 & $\begin{array}{l}\text { This observational study established post-intubation hypotension as an } \\
\text { independent predictor of mortality, longer ICU stay, and longer hospital } \\
\text { stay. }\end{array}$ \\
\hline 2012 & Heffner A. et al. & $J$ Crit Care 2012; 27: 587-593 & $\begin{array}{l}\text { This observational study established shock index as a significant predictor of } \\
\text { post-intubation hypotension. }\end{array}$ \\
\hline 2012 & Wilcox S. et al. & Crit Care Med 2012; 40: 1808-1813 & $\begin{array}{l}\text { This observational study established RSI in ICU as associated with reduced } \\
\text { complications and improved success and intubating conditions. }\end{array}$ \\
\hline 2013 & De Jong A. et al. & Am J Respir Crit Care Med 2013; 187: 832-839 & $\begin{array}{l}\text { This study developed and validated the MACOCHA score to predict difficult } \\
\text { airways in the ICU population. }\end{array}$ \\
\hline 2013 & McPhee L. et al. & Crit Care Med 2013; 41: 774-783 & $\begin{array}{l}\text { This study established that etomidate for RSI in ICU patients with sepsis, } \\
\text { severe sepsis, or septic shock has no association with mortality or } \\
\text { vasopressor requirement. }\end{array}$ \\
\hline 2013 & Sakles J. et al. & Acad Emerg Med 2013; 20: 71-78 & $\begin{array}{l}\text { This study established first-attempt success as the indicator of safety in } \\
\text { emergency airway management, as the second attempt was associated with } \\
\text { a } 40 \% \text { increase in adverse events. }\end{array}$ \\
\hline 2014 & De Jong A. et al. & Intensive Care Med 2014; 40: 629-639 & $\begin{array}{l}\text { This meta-analysis showed VL was associated with increased odds of } \\
\text { first-attempt success, fewer difficult intubations, and reduced complications } \\
\text { compared to DL. }\end{array}$ \\
\hline 2015 & Mosier J. et al. & Ann Am Thorac Soc 2015; 12: 734-741 & $\begin{array}{l}\text { This study confirmed RSI in ICU patients is associated with improved odds of } \\
\text { first-attempt success and reduced complications. }\end{array}$ \\
\hline 2016 & Hypes C. et al. & Ann Am Thorac Soc 2016; 13: 382-390 & $\begin{array}{l}\text { This study confirmed VL was associated with increased odds of first-attempt } \\
\text { success in ICU patients. }\end{array}$ \\
\hline 2017 & Driver B. et al. & Ann Emerg Med 2017; 69: 1-6 & $\begin{array}{l}\text { This study established "flush rate" oxygen as an optimal method for } \\
\text { denitrogenation. }\end{array}$ \\
\hline 2017 & Hypes C. et al. & Intern Emerg Med 2017; 12: 1235-1243 & $\begin{array}{l}\text { This study confirmed that first-attempt success is the measure of safety in ICU } \\
\text { patients, with a } 40 \% \text { increase in complications on the second attempt, and } \\
\text { extended the knowledge that physiological abnormalities increase the risk of } \\
\text { complications despite first-attempt success. }\end{array}$ \\
\hline 2017 & Lascarrou J. et al. & Jama 2017; 317: 483-493 & This RCT showed no difference in outcomes between VL and DL in the ICU. \\
\hline 2018 & Higgs A. et al. & Br J Anaesth 2018; 120: 323-352 & $\begin{array}{l}\text { This guideline is the first evidence-based guideline for airway management in } \\
\text { critically ill patients. }\end{array}$ \\
\hline 2018 & Taboada M. et al. & Anesthesiology 2018; 129: 321-328 & $\begin{array}{l}\text { This study established that patients intubated in the ICU within a month of an } \\
\text { elective OR intubation by the same group of anesthesiologists had worse } \\
\text { views, more complications, and fewer first-attempt successes. }\end{array}$ \\
\hline 2019 & Frat J. et al. & Lancet Respir Med 2019; 7: 303-312 & $\begin{array}{l}\text { This study established HFNO and NIPPV as equivalent for preoxygenation in } \\
\text { patients with acute hypoxemic respiratory failure, except for those with the } \\
\text { most severe shunt (PF }<200 \text { ), where NIPPV provided the best } \\
\text { preoxygenation. }\end{array}$ \\
\hline 2019 & Casey J. et al. & N Engl J Med 2019; 380: 811-821 & $\begin{array}{l}\text { This study established mask ventilation between induction and laryngoscopy } \\
\text { reduced desaturation rates without increased aspiration rates in ICU patients } \\
\text { at low risk of aspiration. }\end{array}$ \\
\hline 2019 & Janz D. et al. & Lancet Respir Med 2019; 7: 1039-1047 & $\begin{array}{l}\text { This trial showed that starting a fluid bolus in undifferentiated ICU patients did } \\
\text { not reduce the rate of cardiovascular collapse. }\end{array}$ \\
\hline 2020 & April M. et al. & Acad Emerg Med 2020; 27: 1106-1115. 2020/06/28 & $\begin{array}{l}\text { This study showed that ketamine was associated with more post-intubation } \\
\text { hypotension in undifferentiated normotensive ED patients. }\end{array}$ \\
\hline 2020 & Brown M. et al. & Acad Emerg Med 2020; 27: 100-108 & $\begin{array}{l}\text { This study showed that VL was associated with increased odds of first-attempt } \\
\text { success compared to various configurations of "augmented" direct } \\
\text { laryngoscopy. }\end{array}$ \\
\hline 2020 & Khan A. et al. & Anaesthesia 2020; 75: 634-641 & $\begin{array}{l}\text { This trial showed no difference in hypotension rates despite goal-directed fluid } \\
\text { resuscitation prior to induction. }\end{array}$ \\
\hline 2020 & Mohr N. et al. & Acad Emerg Med 2020; 27: 1140-1149 & $\begin{array}{l}\text { This study showed ketamine was associated with more post-intubation } \\
\text { hypotension than etomidate in ED patients with sepsis. }\end{array}$ \\
\hline
\end{tabular}


Although NIPPV provides better preoxygenation for severe hypoxemia in patients where RSI is performed, still nearly $25 \%$ of patients desaturated $[24,34 \bullet \cdot]$. Some patients are so severely hypoxemic that safe apnea is not possible despite optimal preoxygenation. RSI in these patients is a race to the bottom of the cliff (that is, cardiac arrest) between one's laryngoscopy skill and the patient's rapid desaturation. While the operator's laryngoscopy skill may be second-to-none, this is still very dangerous for the patient, especially if any difficulty is encountered that delays the onset of mechanical ventilation. These patients are likely more safely intubated awake and spontaneously breathing [12•]. This not only alleviates the requirement of safe apnea for RSI, but also leverages the regional physiology that occurs in spontaneously breathing patients with ARDS - the very physiology that must be eliminated after intubation to avoid patient self-inflicted lung injury.

We stratify our preoxygenation strategy based on the severity of the patient's hypoxemia, the risk of desaturation, and factor in the potential anatomic difficulty that may delay a rapid intubation (see Table 1).

\section{Hemodynamics}

From the battlefield to the ICU, compromised hemodynamics in critically ill patients undergoing airway management is a common and consequential phenomenon. Peri-intubation hemodynamic compromise is associated with longer inpatient stays, increased duration of mechanical ventilation, increased need for renal replacement therapy, and decreased likelihood of survival [44-48]. Therefore, resuscitation is a vital part of airway management in this population, but data regarding peri-intubation resuscitation are limited. This includes the lack of a standard definition, delineation of timing pre- or postintubation, and vital sign thresholds.

Cardiovascular collapse and shock after intubation are not newly recognized phenomena. We have always sought to reduce this risk, thus the seemingly unending debate over etomidate as an induction agent in sepsis. Common practice is to resuscitate prior to intubation. A recent large national survey showed that most physicians are likely to use crystalloid resuscitation prior to emergency airway management, especially in patients requiring intubation for trauma or pneumonia [49]. Respondents are more likely to use vasopressors in patients with heart failure [49].

Even though we are mindful of peri-intubation hypotension rates (reported in $30-46 \%$ of patients), predicting an individual patient's risk of cardiovascular collapse during intubation remains challenging. An elevated shock index is a specific but insensitive marker of post-intubation hypotension [45-47, 50-53]. Recent regression analyses and two recent prediction scores have been developed, which all find that in general, older age, hypotension or shock prior to intubation, intubation for respiratory failure, and higher APACHE score are all strong predictors of post-intubation cardiovascular collapse $[52,54-56]$.

If predicting cardiovascular collapse is challenging, preventing it is even more elusive. Resuscitation was included in an intubation bundle that successfully decreased complications in an ICU setting [57]. Unfortunately, replicating that finding in recent trials has been less successful. In a randomized controlled trial of normotensive patients, which excluded patients in whom fluids were indicated per clinical assessment and one-third of patients were already on vasopressors, initiation of a 500-ml crystalloid bolus did not decrease the chances of hemodynamic collapse compared to not initiating a bolus [58]. Longer ICU lengths-of-stay, longer duration of mechanical ventilation, and decreased survival were seen in patients in whom cardiovascular collapse occurred regardless of the group to which they were randomized [58]. Fluid optimization prior to induction in an operating room setting did not show a difference in outcomes, and one-third of the patients were on vasopressors within 15 min of induction regardless of goal-directed optimization [59]. Interestingly, a pre-intubation blood product-based resuscitation reduced the incidence of hypotension, cardiac arrest, and mortality in injured combat troops, [48] indicating that in the right patients, fluid resuscitation is useful to improve outcomes.

Induction medication choice also serves as a point of intervention to reduce cardiovascular collapse and is often a source of heated debates. Propofol and midazolam at RSI doses are potent venodilators. Etomidate evolved as the solution to that venodilation as it is considered "hemodynamically neutral," but itself has long been debated over fear of adrenal suppression $[60,61]$. Ketamine emerged as an alternative agent for patients with sepsis for its desirable indirect sympathomimetic effect [62-64], and in some forums, it is considered a buffer against all hemodynamic problems. However, there is no good evidence that etomidate-related transient adrenal insufficiency worsens outcomes, and recent evidence shows that hypotension from etomidate may be mediated through a reduced arterial elastance rather than adrenal suppression [65]. Furthermore ketamine is also a direct myocardial depressant that has been associated with cardiac arrest during RSI, and very recent observational studies showed ketamine to be associated with worse hypotension rates than etomidate, especially when propensity-matched $[66,67 \bullet]$. 
Just as with preoxygenation where the approach requires personalization based on the underlying physiology, so too is the case with a patient's hemodynamics. Regardless of the lack of definitive data, clear definitions, and lackluster data on interventions, the physiological rationale for resuscitation prior to intubation in the critically ill is logical and prudent. Reduced effective circulating volume, vasoplegia, and sympatholytic medications all become exaggerated during the transition to positive pressure ventilation, causing further loss in preload [3, 68-70] However, indiscriminate fluid boluses or relying on side effects of induction medications will not reduce danger from cardiovascular collapse in isolation.

In reality, the peri-intubation cardiopulmonary interactions are likely much more complex than simply volume depletion, vasodilating induction drugs, and positive pressure-mediated reduction in preload. In supine, spontaneously breathing patients, diaphragm displacement is predominantly dorsal, leading to an increase in FRC and improved ventilation to perfusion matching in the dependent lung zones [71-74] In patients with ARDS, this is exaggerated through transpulmonary force amplification mediated by regional stress risers. Eliminating spontaneous breathing with any induction agent leads to a loss in that dependent diaphragm displacement, loss of FRC, dependent atelectasis, worsened ventilation to perfusion mismatch, increased pulmonary vascular resistance, and a reduced cardiac output. Mask or mechanical ventilation in these patients results in predominantly ventral diaphragm displacement, which fails to restore the physiological benefits of spontaneous breathing. Any disturbance in any variable within this complex interaction can be the trigger for cardiovascular collapse rather than just transient hypotension.

For example, ARDS patients have reduced FRC and increased pulmonary vascular resistance. Patients with decompensated right ventricular failure do not have reserve for increases in pulmonary vascular resistance. Patients with left ventricular failure, restrictive physiology, or constrictive pericarditis may not have tolerance for the reductions in venous return from volume depletion or contractility from ketamine. Patients with vasoplegia may not have reserve for reduced arterial elastance from etomidate, and those with septic cardiomyopathy may not tolerate myocardial depression from ketamine. Hemodynamic management is complex, and requires more personalized nuance than indiscriminate fluid administration, rescue vasopressors, or a single induction choice.

When feasible, we recommend assessing for evidence of volume responsiveness and volume tolerance, as well as ventricular function to understand the hemodynamic challenges to patient safety with intubation. Ultrasonography allows for rapid assessment of each of these aspects of hemodynamics [75] and allows for a more in-depth evaluation of potential threats. For example, ultrasound permits a more nuanced assessment of volume tolerance, diastolic function, and atrial pressures for patients with left ventricular disease; contractile reserve, systolic function, and volume status in patients with right ventricular disease; and response to fluid challenges in patients with vasoplegia. We recommend volume expansion in responders and using vasopressors in nonresponders, preferably as an infusion and especially in patients at risk of cardiovascular collapse based on pre-intubation assessment or shock index $\geq 0.8$. Peripheral venous lines can safely be used to infuse vasopressors [76], with norepinephrine as the preferred agent. Vasopressors given as an IV bolus (i.e., "Push Dose") vasopressors have been safely and effectively used in this scenario $[77,78]$, but rescue push dose vasopressors should be reserved for transient unexpected decreases in otherwise hemodynamically stable patients. Push dose phenylephrine should be used cautiously due to concern about increased blood pressure but a reduction in cardiac output [78, 79]. Pharmacologic agents used for preparation, sedation, and induction play an important role and should be personalized. Patients with right ventricular (RV) failure should have an RV-guided resuscitation to avoid the dangerous spiral of decreased RV systolic function, RV pressure/volume overload, decreased left ventricular filling, decreased cardiac output, and hypotension [3, 80]. This includes pulmonary vasodilators to reduce $\mathrm{RV}$ afterload; norepinephrine to increase mean arterial pressure, coronary perfusion pressure, and in some cases RV contractility; and diuretics if RV volume overload is present. In general, pre-intubation resuscitation can reduce having to rely on beneficial, or react to undesirable, side effects of the induction agents to prevent complications. Our standard practice is pre-intubation resuscitation and use of fulldose etomidate and rocuronium when RSI is planned. Just as in preoxygenation, though, some patients are so fragile that an awake approach should be considered. We recommend that patients with complex, refractory disease, where more than one untoward effect of induction and transition to positive pressure is a risk should be considered for an awake intubation where feasible. An example would be a patient with decompensated right ventricular failure, where the combined effects of the loss of spontaneous breathing and positive pressure ventilation on pulmonary vascular resistance, and hypotension from induction medications may precipitate cardiac arrest. See Table 1 for further recommendations.

\section{Preparation}

Time sensitivity during emergency airway management often does not allow for adequate pre-procedural assessment and preparation. Regardless, some assessment of anatomic and physiologic factors that may make airway management difficult for the operator and dangerous for the patient must be carried out. A systematic approach with succeeding plans and a checklist is highly recommended. Conducting a preintubation assessment; creating and communicating an intubation strategy that includes backup plans; acquiring the 
necessary equipment and help; and positioning, preoxygenation, and hemodynamic resuscitation can all occur concurrently [2], and can be abbreviated when required such as with a crash airway where cardiac arrest is imminent. The LEMON mnemonic can be used to assess difficulties with laryngoscopy [81], but ignores physiological abnormalities. The MACHOCA score was developed and validated in the ICU population and accounts for physiological abnormalities (hypoxemia), but has not been validated for video laryngoscopy (VL) [82]. In addition to difficulty with laryngoscopy, potential difficulty with mask ventilation, supraglottic airway placement, and cricothyrotomy should also be assessed to inform the airway management strategy [83-87].

Just as positioning is important for preoxygenation, positioning is important for the laryngoscopic view of the airway and tube placement. The sniffing position with neck flexion and head extension has long been considered the standard, but ramped position with "bed-up-head-elevated" (BUHE) positions have also shown advantages [88-90]. Despite lack of clear data on cricoid pressure as a measure to prevent aspiration [91-93], including data that it worsens laryngoscopic view [93-95], it remains part of airway management guidelines [2]. In patients at high risk of aspiration, bedside gastric ultrasonography can identify patients that may benefit from cricoid pressure or, even better, gastric decompression prior to laryngoscopy [96, 97].

Based on anatomic and physiological assessment as well as optimization opportunity, a plan may be developed in terms of approach, device selection, and pharmacologic options, along with consideration of why the initial attempt may not be successful. A successive "plan B," therefore, must include maneuvers or techniques that may overcome the point of failure of the initial plan and preparation to perform that plan. Checklists allow for patient optimization, promote a disciplined and systematic approach with a shared mental model for airway management, and they can ensure that appropriate personnel, equipment, and medications are prepared prior to intubation. Finally, operator training and experience is a contributing factor of success but does not replace planning and preparation. Out-of OR airway management, when compared to routine management in the OR, increases difficulty and complications, despite being performed by the same operators [98]. As such, robust curricula and quality improvement programs should be considered to improve overall intubation safety in EDs and ICUs [99, 100].

\section{Devices}

The smoldering debate over direct laryngoscopy versus VL continues in critically ill patients as the data remain conflicted. One complication to interpreting the data is the definition of VL. While putting a camera on the end of a laryngoscope blade makes a video laryngoscope, the geometry of the blade affects performance and thus traditional Macintosh geometry blades should not be compared to hyperangulated blades. The former is designed for routine use with the benefit of reducing unanticipated difficult intubations, while the latter is designed for patients with predicted difficult intubations. However, on the balance of data, VL provides benefits over direct laryngoscopy with little downside. We routinely use VL (traditional geometry for routine airways and hyperangulated for predicted difficult airways) and train our fellows extensively on VL. As the senior author stated in a recent paper, VL has been shown in the literature to improve the grade of view (which directly correlates with desaturation risk $[101 \bullet \bullet]$ ), reduce difficult intubations (which are difficult to predict), reduce airway trauma, aid faster skill acquisition in both experienced operators and novices, and improve successful intubations in patients with difficult airways $[1 \bullet]$, even compared to "optimized" direct laryngoscopy [102].

One recent clinical trial performed in a single ED showed that the routine use of a bougie can further increase firstattempt success when using either direct laryngoscopy or traditional geometry VL [103]. While a multicenter study is ongoing (NCT03928925) to replicate the results of this trial, the major lesson learned is that a systematic training program and routine use of traditional geometry VL with a bougie can achieve a $96 \%$ first-attempt success rate in patients with any difficult airway characteristic, $98 \%$ in all patients [103]. When difficulty is encountered and mask ventilation cannot accomplish reoxygenation, supraglottic airways have been shown to restore oxygenation most of the time [104], and provide a conduit for tracheal intubation when combined with a flexible endoscope - which are now widely available, disposable, and cost-effective.

\section{Intubation in COVID-19}

Intubation in patients with COVID-19 initially presented a challenge not generally considered in the airway management plan - risk of infection to healthcare workers. There was fear over bioaerosol production leading to transmission of infectious particles that increase the risk of infecting the healthcare team. This fear prompted several recommendations, including (1) avoiding high-flow nasal oxygen or noninvasive ventilation, (2) performing all intubations by RSI, (3) avoiding mask ventilation, (4) using video laryngoscopy to increase distance between the patient and operator, and (5) using a barrier device like a plexiglass intubation box. These recommendations were prudent given the information available at the time, and given the widespread lack of protective equipment for staff; however, over the last year, we have gained significant knowledge to inform our practice. There is now evidence that highflow nasal cannulas and noninvasive ventilation have no increased aerosol production compared to standard nasal 
cannula or facemask oxygen $[105,106]$. While a benefit of both RSI and video laryngoscopy is a reduction in aerosol production and increased distance from the operator to the patient, respectively, the major reason both should be used routinely is for the improvement in first-attempt success that we already knew prior to COVID-19. Not mask ventilating patients and not performing awake intubations in indicated patients are potentially harmful recommendations given what we know now, and in the presence of adequate personal protective equipment. We also now know that intubation boxes do not reduce aerosol exposure and are potentially harmful for patients when the operator is faced with any difficulty [107-109]. One remaining challenge for teams to address, however, is communication between members of the intubation team, where face shields, masks, and hoods severely diminish the ability to verbally and nonverbally communicate. Teams should prepare and rehearse for crisis situations during intubation given these limitations.

\section{Conclusion}

Airway management in critically ill patients has advanced over the last decade, with important knowledge gained on the risk of cardiac arrest imposed by physiological disturbances. Despite significant technological advances that reduce the incidence of and optimize the management of difficult airways, more research is needed to better determine how to predict and prevent cardiac arrest and severe hypoxemia in critically ill patients.

\section{Declarations}

Conflict of Interest Bhupinder Natt declares that he has no conflict of interest. Jarrod Mosier serves on an advisory board for Verathon Medical, and has received non-financial support (equipment) as a result.

\section{References}

Papers of particular interest, published recently, have been highlighted as:

- Of importance

•. Of major importance

1. Mosier JM, Sakles JC, Law JA, Brown CA 3rd, Brindley PG. Tracheal intubation in the critically ill. Where we came from and where we should go. Am J Respir Crit Care Med. 2020;201(7): 775-88. https://doi.org/10.1164/rccm.201908-1636CI This article reviews the history of airway management in critically ill patients and comprehensively reviews the literature and makes recommendations on future research directions.
2. Higgs A, McGrath BA, Goddard C, Rangasami J, Suntharalingam $\mathrm{G}$, Gale R, et al. Guidelines for the management of tracheal intubation in critically ill adults. Br J Anaesth. 2018;120(2):323-52. https://doi.org/10.1016/j.bja.2017.10.021.

3. Mosier JM, Joshi R, Hypes C, Pacheco G, Valenzuela T, Sakles JC. The physiologically difficult airway. West J Emerg Med. 2015;16(7):1109-17. https://doi.org/10.5811/westjem.2015.8. 27467.

4. Snow RG, Nunn JF. Induction of anaesthesia in the foot-down position for patients with a full stomach. Br J Anaesth. 1959;31: 493-7. https://doi.org/10.1093/bja/31.11.493.

5. Stept WJ, Safar P. Rapid induction-intubation for prevention of gastric-content aspiration. Anesth Analg. 1970;49(4):633-6.

6. Wylie WD. The use of muscle relaxants at the induction of anaesthesia of patients with a full stomach. Br J Anaesth. 1963;35:168 73. https://doi.org/10.1093/bja/35.3.168.

7. De Jong A, Rolle A, Molinari N, Paugam-Burtz C, Constantin JM, Lefrant JY, et al. Cardiac arrest and mortality related to intubation procedure in critically ill adult patients: a multicenter cohort study. Crit Care Med. 2018;46(4):532-9. https://doi.org/10.1097/CCM. 0000000000002925.

8. McKown AC, Casey JD, Russell DW, Joffe AM, Janz DR, Rice $\mathrm{TW}$, et al. Risk factors for and prediction of hypoxemia during tracheal intubation of critically ill adults. Ann Am Thorac Soc. 2018;15(11):1320-7. https://doi.org/10.1513/AnnalsATS. 201802-118OC.

9. Smischney NJ, Seisa MO, Heise KJ, Wiegand RA, Busack KD, Loftsgard TO, et al. Predictors of arterial desaturation during intubation: a nested case-control study of airway management-part I. J Thorac Dis. 2017;9(10):3996-4005. https://doi.org/10.21037/ jtd.2017.08.138.

10. Mort TC. Preoxygenation in critically ill patients requiring emergency tracheal intubation. Crit Care Med. 2005;33(11):2672-5. https://doi.org/10.1097/01.ccm.0000187131.67594.9e.

11. Mort TC, Waberski BH, Clive J. Extending the preoxygenation period from 4 to $8 \mathrm{mins}$ in critically ill patients undergoing emergency intubation. Crit Care Med. 2009;37(1):68-71. https://doi. org/10.1097/CCM.0b013e318192845e.

12. Mosier JM. Physiologically difficult airway in critically ill patients: winning the race between haemoglobin desaturation and tracheal intubation. Br J Anaesth. 2020;125(1):e1-4. https://doi. org/10.1016/j.bja.2019.12.001 This article details the risk of desaturation with patients with hypoxemic respiratory failure and explains the physiological rationale for awake intubation in the most severe patients.

13. Mosier JM, Hypes CD, Sakles JC. Understanding preoxygenation and apneic oxygenation during intubation in the critically ill. Intensive Care Med. 2017;43(2):226-8. https://doi.org/10.1007/ s00134-016-4426-0.

14. Nimmagadda U, Salem MR, Joseph NJ, Lopez G, Megally M, Lang DJ, et al. Efficacy of preoxygenation with tidal volume breathing: comparison of breathing systems. Anesthesiology. 2000;93(3):693-8. https://doi.org/10.1097/00000542200009000-00018.

15. Groombridge $\mathrm{C}$, Chin CW, Hanrahan B, Holdgate A. Assessment of common preoxygenation strategies outside of the operating room environment. Acad Emerg Med. 2016;23(3):342-6. https:// doi.org/10.1111/acem.12889.

16. Hayes-Bradley C, Lewis A, Burns B, Miller M. Efficacy of nasal cannula oxygen as a preoxygenation adjunct in emergency airway management. Ann Emerg Med. 2016;68(2):174-80. https://doi. org/10.1016/j.annemergmed.2015.11.012.

17. Hanouz JL, Lammens S, Tasle M, Lesage A, Gerard JL, Plaud B. Preoxygenation by spontaneous breathing or noninvasive positive pressure ventilation with and without positive end-expiratory pressure: a randomised controlled trial. Eur J Anaesthesiol. 
2015;32(12):881-7. https://doi.org/10.1097/EJA. 0000000000000297.

18. McQuade D, Miller MR, Hayes-Bradley C. Addition of nasal cannula can either impair or enhance preoxygenation with a bag valve mask: a randomized crossover design study comparing oxygen flow rates. Anesth Analg. 2018;126(4):1214-8. https://doi. org/10.1213/ANE.0000000000002341.

19. Driver BE, Prekker ME, Kornas RL, Cales EK, Reardon RF. Flush rate oxygen for emergency airway preoxygenation. Ann Emerg Med. 2017;69(1):1-6. https://doi.org/10.1016/j. annemergmed.2016.06.018.

20. Mosier J, Reardon RF, DeVries PA, Stang JL, Nelsen A, Prekker $\mathrm{ME}$, et al. Time to loss of preoxygenation in emergency department patients. J Emerg Med. 2020;59(5):637-42. https://doi.org/ 10.1016/j.jemermed.2020.06.064.

21. Doyle AJ, Stolady D, Mariyaselvam M, Wijewardena G, Gent E, Blunt $\mathrm{M}$, et al. Preoxygenation and apneic oxygenation using transnasal humidified rapid-insufflation ventilatory exchange for emergency intubation. J Crit Care. 2016;36:8-12. https://doi.org/ 10.1016/j.jcrc.2016.06.011.

22. Jaber S, Monnin M, Girard M, Conseil M, Cisse M, Carr J, et al. Apnoeic oxygenation via high-flow nasal cannula oxygen combined with non-invasive ventilation preoxygenation for intubation in hypoxaemic patients in the intensive care unit: the single-centre, blinded, randomised controlled OPTINIV trial. Intensive Care Med. 2016;42(12):1877-87. https://doi.org/10.1007/s00134-0164588-9.

23. Hengen M, Willemain R, Meyer A, Langer B, Joshi GP, Diemunsch $P$. Transnasal humidified rapid-insufflation ventilatory exchange for preoxygenation before cesarean delivery under general anesthesia: a case report. A A Case Rep. 2017;9(7):216-8. https://doi.org/10.1213/XAA.0000000000000571.

24. Guitton C, Ehrmann S, Volteau C, Colin G, Maamar A, JeanMichel V, et al. Nasal high-flow preoxygenation for endotracheal intubation in the critically ill patient: a randomized clinical trial. Intensive Care Med. 2019;45(4):447-58. https://doi.org/10.1007/ s00134-019-05529-w.

25. Caputo N, Azan B, Domingues R, Donner L, Fenig M, Fields D, et al. Emergency department use of apneic oxygenation versus usual care during rapid sequence intubation: a randomized controlled trial (The ENDAO Trial). Acad Emerg Med. 2017;24(11): 1387-94. https://doi.org/10.1111/acem.13274.

26. Mir F, Patel A, Iqbal R, Cecconi M, Nouraei SAR. A randomised controlled trial comparing transnasal humidified rapid insufflation ventilatory exchange (THRIVE) pre-oxygenation with facemask pre-oxygenation in patients undergoing rapid sequence induction of anaesthesia. Anaesthesia. 2017;72(4):439-43. https://doi.org/ 10.1111/anae.13799.

27. Oliveira JESL, Cabrera D, Barrionuevo P, Johnson RL, Erwin PJ, Murad MH, et al. Effectiveness of apneic oxygenation during intubation: a systematic review and meta-analysis. Ann Emerg Med. 2017;70(4):483-94 e11. https://doi.org/10.1016/j. annemergmed.2017.05.001.

28. Semler MW, Janz DR, Lentz RJ, Matthews DT, Norman BC, Assad TR, et al. Randomized trial of apneic oxygenation during endotracheal intubation of the critically ill. Am J Respir Crit Care Med. 2015;193:273-80. https://doi.org/10.1164/rccm.2015071294OC.

29. Engström J, Hedenstierna G, Larsson A. Pharyngeal oxygen administration increases the time to serious desaturation at intubation in acute lung injury: an experimental study. Crit Care. 2010;14(3): R93. https://doi.org/10.1186/cc9027.

30. Ramkumar V, Umesh G, Philip FA. Preoxygenation with $20^{\circ}$ head-up tilt provides longer duration of non-hypoxic apnea than conventional preoxygenation in non-obese healthy adults. J
Anesth. 2011;25(2):189-94. https://doi.org/10.1007/s00540-0111098-3.

31. Baillard C, Prat G, Jung B, Futier E, Lefrant JY, Vincent F, et al. Effect of preoxygenation using non-invasive ventilation before intubation on subsequent organ failures in hypoxaemic patients: a randomised clinical trial. Br J Anaesth. 2018;120(2):361-7. https://doi.org/10.1016/j.bja.2017.11.067.

32. Bailly A, Ricard JD, Le Thuaut A, Helms J, Kamel T, Mercier E, et al. Compared efficacy of four preoxygenation methods for intubation in the ICU: retrospective analysis of McGrath Mac Videolaryngoscope Versus Macintosh Laryngoscope (MACMAN) Trial Data. Crit Care Med. 2019;47(4):e340-e8. https://doi.org/10.1097/ccm.0000000000003656.

33. Fong KM, Au SY, Ng GWY. Preoxygenation before intubation in adult patients with acute hypoxemic respiratory failure: a network meta-analysis of randomized trials. Crit Care. 2019;23(1):319. https://doi.org/10.1186/s13054-019-2596-1.

34.• Frat JP, Ricard JD, Quenot JP, Pichon N, Demoule A, Forel JM, et al. Non-invasive ventilation versus high-flow nasal cannula oxygen therapy with apnoeic oxygenation for preoxygenation before intubation of patients with acute hypoxaemic respiratory failure: a randomised, multicentre, open-label trial. Lancet Respir Med. 2019;7(4):303-12. https://doi.org/10.1016/s2213-2600(19) 30048-7 This article compares HFNO and NIPPV for preoxygenation in patients with acute hypoxemic respiratory failure, and establishes that they have similar outcomes, but in the most severe patients, NIPPV may have better performance.

35. Casey JD, Janz DR, Russell DW, Vonderhaar DJ, Joffe AM, Dischert KM, et al. Manual ventilation to prevent hypoxaemia during endotracheal intubation of critically ill adults: protocol and statistical analysis plan for a multicentre randomised trial. BMJ Open. 2018;8(8):e022139. https://doi.org/10.1136/ bmjopen-2018-022139.

36. Baillard C, Fosse JP, Sebbane M, Chanques G, Vincent F, Courouble $P$, et al. Noninvasive ventilation improves preoxygenation before intubation of hypoxic patients. Am J Respir Crit Care Med. 2006;174(2):171-7. https://doi.org/10. 1164/rccm.200509-1507OC.

37. Vourc'h M, Asfar P, Volteau C, Bachoumas K, Clavieras N, Egreteau P-Y, et al. High-flow nasal cannula oxygen during endotracheal intubation in hypoxemic patients: a randomized controlled clinical trial. Intensive Care Med. 2015;41(9):1538-48. https://doi.org/10.1007/s00134-015-3796-z.

38. Besnier E, Guernon K, Bubenheim M, Gouin P, Carpentier D, Beduneau G, et al. Pre-oxygenation with high-flow nasal cannula oxygen therapy and non-invasive ventilation for intubation in the intensive care unit. Intensive Care Med. 2016;42(8):1291-2. https://doi.org/10.1007/s00134-016-4369-5.

39. Simon M, Wachs C, Braune S, de Heer G, Frings D, Kluge S. High-flow nasal cannula versus bag-valve-mask for preoxygenation before intubation in subjects with hypoxemic respiratory failure. Respir Care. 2016;61(9):1160-7. https://doi.org/ 10.4187/respcare.04413.

40. Raineri SM, Cortegiani A, Accurso G, Procaccianti C, Vitale F, Caruso S, et al. Efficacy and safety of using high-flow nasal oxygenation in patients undergoing rapid sequence intubation. Turk $\mathrm{J}$ Anaesthesiol Reanim. 2017;45(6):335-9. https://doi.org/10.5152/ tjar.2017.47048.

41. Lodenius A, Piehl J, Ostlund A, Ullman J, Fagerlund MJ. Transnasal humidified rapid-insufflation ventilatory exchange (THRIVE) vs. facemask breathing pre-oxygenation for rapid sequence induction in adults: a prospective randomised non-blinded clinical trial. Anaesthesia. 2018;73(5):564-71. https://doi.org/10. 1111/anae.14215. 
42. Miguel-Montanes R, Hajage D, Messika J, Bertrand F, Gaudry S, Rafat C, et al. Use of high-flow nasal cannula oxygen therapy to prevent desaturation during tracheal intubation of intensive care patients with mild-to-moderate hypoxemia. Crit Care Med. 2015;43(3):574-83. https://doi.org/10.1097/CCM. 0000000000000743.

43. Patel A, Nouraei SA. Transnasal Humidified Rapid-Insufflation Ventilatory Exchange (THRIVE): a physiological method of increasing apnoea time in patients with difficult airways. Anaesthesia. 2015;70(3):323-9. https://doi.org/10.1111/anae. 12923.

44. Green RS, Edwards J, Sabri E, Fergusson D. Evaluation of the incidence, risk factors, and impact on patient outcomes of postintubation hemodynamic instability. CJEM. 2012;14(2):7482. https://doi.org/10.2310/8000.2012.110548.

45. Heffner AC, Swords D, Kline JA, Jones AE. The frequency and significance of postintubation hypotension during emergency airway management. J Crit Care. 2012;27(4):417 e9-13. https://doi. org/10.1016/j.jcrc.2011.08.011.

46. Green RS, Turgeon AF, McIntyre LA, Fox-Robichaud AE, Fergusson DA, Doucette S, et al. Postintubation hypotension in intensive care unit patients: a multicenter cohort study. J Crit Care. 2015;30(5):1055-60. https://doi.org/10.1016/j.jcrc.2015.06.007.

47. Perbet S, De Jong A, Delmas J, Futier E, Pereira B, Jaber S, et al. Incidence of and risk factors for severe cardiovascular collapse after endotracheal intubation in the ICU: a multicenter observational study. Crit Care. 2015;19:257. https://doi.org/10.1186/ s13054-015-0975-9.

48. Emerling AD, Bianchi W, Krzyzaniak M, Deaton T, Via D, Archer B, et al. Rapid sequence induction strategies among critically injured U.S. military during the Afghanistan and Iraq conflicts. Mil Med. 2021;186(Suppl 1):316-23. https://doi.org/10. 1093/milmed/usaa356.

49. Green RS, Fergusson DA, Turgeon AF, McIntyre LA, Kovacs GJ, Griesdale DE, et al. Resuscitation prior to emergency endotracheal intubation: results of a national survey. West J Emerg Med. 2016;17(5):542-8. https://doi.org/10.5811/westjem.2016.6. 30503.

50. Heffner AC, Swords DS, Nussbaum ML, Kline JA, Jones AE. Predictors of the complication of postintubation hypotension during emergency airway management. J Crit Care. 2012;27(6):58793. https://doi.org/10.1016/j.jcrc.2012.04.022.

51. Trivedi S, Demirci O, Arteaga G, Kashyap R, Smischney NJ. Evaluation of preintubation shock index and modified shock index as predictors of postintubation hypotension and other short-term outcomes. J Crit Care. 2015;30(4):861 e1-7. https://doi.org/10. 1016/j.jcrc.2015.04.013.

52. Smischney NJ, Kashyap R, Khanna AK, Brauer E, Morrow LE, Seisa MO, et al. Risk factors for and prediction of post-intubation hypotension in critically ill adults: a multicenter prospective cohort study. PLoS One. 2020;15(8):e0233852. https://doi.org/10. 1371/journal.pone.0233852.

53. Smischney NJ, Demirci O, Diedrich DA, Barbara DW, Sandefur $\mathrm{BJ}$, Trivedi S, et al. Incidence of and risk factors for postintubation hypotension in the critically ill. Med Sci Monit. 2016;22:346-55. https://doi.org/10.12659/msm.895919.

54. Halliday SJ, Casey JD, Rice TW, Semler MW, Janz DR, Russell $\mathrm{DW}$, et al. Risk factors for cardiovascular collapse during tracheal intubation of critically ill adults. Ann Am Thorac Soc. 2020;17(8): 1021-4. https://doi.org/10.1513/AnnalsATS.201912-894RL.

55. Kim JM, Shin TG, Hwang SY, Yoon H, Cha WC, Sim MS, et al. Sedative dose and patient variable impacts on postintubation hypotension in emergency airway management. Am J Emerg Med. 2019;37(7):1248-53. https://doi.org/10.1016/j.ajem.2018.09.015.

56. Lee K, Jang JS, Kim J, Suh YJ. Age shock index, shock index, and modified shock index for predicting postintubation hypotension in the emergency department. Am J Emerg Med. 2020;38(5):911-5. https://doi.org/10.1016/j.ajem.2019.07.011.

57. Jaber S, Jung B, Corne P, Sebbane M, Muller L, Chanques G, et al. An intervention to decrease complications related to endotracheal intubation in the intensive care unit: a prospective, multiple-center study. Intensive Care Med. 2010;36(2):248-55. https://doi.org/10.1007/s00134-009-1717-8.

58. Janz DR, Casey JD, Semler MW, Russell DW, Dargin J, Vonderhaar DJ, et al. Effect of a fluid bolus on cardiovascular collapse among critically ill adults undergoing tracheal intubation (PrePARE): a randomised controlled trial. Lancet Respir Med. 2019;7(12):1039-47. https://doi.org/10.1016/S2213-2600(19) 30246-2.

59. Khan AI, Fischer M, Pedoto AC, Seier K, Tan KS, Dalbagni G, et al. The impact of fluid optimisation before induction of anaesthesia on hypotension after induction. Anaesthesia. 2020;75(5): 634-41. https://doi.org/10.1111/anae.14984.

60. Katz J, Greenberg S. Etomidate is not a first-line induction agent in critically ill patients: primum non nocere-above all, do no harm. Crit Care Med. 2018;46(9):1495-6. https://doi.org/10.1097/CCM. 0000000000003291

61. Lynde GC, Jabaley CS. Etomidate is a first-line induction agent in critically ill patients. Crit Care Med. 2018;46(9):1492-4. https:// doi.org/10.1097/CCM.0000000000003290.

62. Jabre P, Combes X, Lapostolle F, Dhaouadi M, Ricard-Hibon A, Vivien B, et al. Etomidate versus ketamine for rapid sequence intubation in acutely ill patients: a multicentre randomised controlled trial. Lancet. 2009;374(9686):293-300. https://doi.org/10. 1016/S0140-6736(09)60949-1.

63. Price B, Arthur AO, Brunko M, Frantz P, Dickson JO, Judge T, et al. Hemodynamic consequences of ketamine vs etomidate for endotracheal intubation in the air medical setting. Am J Emerg Med. 2013;31(7):1124-32. https://doi.org/10.1016/j.ajem.2013. 03.041.

64. Van Berkel MA, Exline MC, Cape KM, Ryder LP, Phillips G, Ali $\mathrm{NA}$, et al. Increased incidence of clinical hypotension with etomidate compared to ketamine for intubation in septic patients: a propensity matched analysis. J Crit Care. 2017;38:209-14. https://doi.org/10.1016/j.jcrc.2016.11.009.

65. Abou Arab O, Fischer MO, Carpentier A, Beyls C, Huette P, Hchikat A, et al. Etomidate-induced hypotension: a pathophysiological approach using arterial elastance. Anaesth Crit Care Pain Med. 2019;38(4):347-52. https://doi.org/10.1016/j.accpm.2018. 12.006 .

66. April MD, Arana A, Schauer SG, Davis WT, Oliver JJ, Fantegrossi A, et al. Ketamine versus etomidate and periintubation hypotension: a national emergency airway registry study. Acad Emerg Med. 2020;27(11):1106-15. https://doi.org/ 10.1111/acem.14063.

67. Mohr NM, Pape SG, Runde D, Kaji AH, Walls RM, Brown CA 3rd. Etomidate use is associated with less hypotension than ketamine for emergency department sepsis intubations: a NEAR cohort study. Acad Emerg Med. 2020;27(11):1140-9. https://doi. org/10.1111/acem.14070 This article shows ketamine is associated with more post-intubation hypotension than etomidate in septic ED patients.

68. Funk DJ, Jacobsohn E, Kumar A. Role of the venous return in critical illness and shock: part II-shock and mechanical ventilation. Crit Care Med. 2013;41(2):573-9. https://doi.org/10.1097/CCM. 0b013e31827bfc25.

69. Funk DJ, Jacobsohn E, Kumar A. The role of venous return in critical illness and shock-part I: physiology. Crit Care Med. 2013;41(1):255-62. https://doi.org/10.1097/CCM. 0b013e3182772ab6.

70. Natt BS, Malo J, Hypes CD, Sakles JC, Mosier JM. Strategies to improve first attempt success at intubation in critically ill patients. 
Br J Anaesth. 2016;117(Suppl 1):i60-i8. https://doi.org/10.1093/ bja/aew061.

71. Froese AB, Bryan AC. Effects of anesthesia and paralysis on diaphragmatic mechanics in man. Anesthesiology. 1974;41(3): 242-55. https://doi.org/10.1097/00000542-197409000-00006.

72. Putensen C, Mutz NJ, Putensen-Himmer G, Zinserling J. Spontaneous breathing during ventilatory support improves ventilation-perfusion distributions in patients with acute respiratory distress syndrome. Am J Respir Crit Care Med. 1999;159(4 Pt 1):1241-8. https://doi.org/10.1164/ajrccm.159.4.9806077.

73. Mauri T, Bellani G, Confalonieri A, Tagliabue P, Turella M, Coppadoro A, et al. Topographic distribution of tidal ventilation in acute respiratory distress syndrome: effects of positive endexpiratory pressure and pressure support. Crit Care Med. 2013;41(7):1664-73. https://doi.org/10.1097/CCM. 0b013e318287f6e7.

74. Yoshida T, Fujino Y, Amato MB, Kavanagh BP. Fifty Years of research in ARDS. spontaneous breathing during mechanical ventilation. Risks, Mechanisms, and Management. Am J Respir Crit Care Med. 2017;195(8):985-92. https://doi.org/10.1164/rccm. 201604-0748CP.

75. de Witt B, Joshi R, Meislin H, Mosier JM. Optimizing oxygen delivery in the critically ill: assessment of volume responsiveness in the septic patient. J Emerg Med. 2014;47(5):608-15. https://doi. org/10.1016/j.jemermed.2014.06.015.

76. Loubani OM, Green RS. A systematic review of extravasation and local tissue injury from administration of vasopressors through peripheral intravenous catheters and central venous catheters. J Crit Care. 2015;30(3):653 e9-17. https://doi.org/10.1016/j.jcrc. 2015.01.014

77. Dyer RA, Reed AR, van Dyk D, Arcache MJ, Hodges O, Lombard CJ, et al. Hemodynamic effects of ephedrine, phenylephrine, and the coadministration of phenylephrine with oxytocin during spinal anesthesia for elective cesarean delivery. Anesthesiology. 2009;111(4):753-65. https://doi.org/10.1097/ ALN.0b013e3181b437e0.

78. Panchal AR, Satyanarayan A, Bahadir JD, Hays D, Mosier J. Efficacy of bolus-dose phenylephrine for peri-intubation hypotension. J Emerg Med. 2015;49(4):488-94. https://doi.org/10.1016/j. jemermed.2015.04.033.

79. Ho AM, Mizubuti GB. Co-induction with a vasopressor "chaser" to mitigate propofol-induced hypotension when intubating critically ill/frail patients-a questionable practice. J Crit Care. 2019;54: 256-60. https://doi.org/10.1016/j.jcrc.2019.09.015.

80. Dalabih M, Rischard F, Mosier JM. What's new: the management of acute right ventricular decompensation of chronic pulmonary hypertension. Intensive Care Med. 2014;40(12):1930-3. https:// doi.org/10.1007/s00134-014-3459-5.

81. Reed MJ, Dunn MJ, McKeown DW. Can an airway assessment score predict difficulty at intubation in the emergency department? Emerg Med J. 2005;22(2):99-102. https://doi.org/10.1136/emj. 2003.008771.

82. De Jong A, Molinari N, Terzi N, Mongardon N, Arnal J-M, Guitton C, et al. Early identification of patients at risk for difficult intubation in the intensive care unit: development and validation of the MACOCHA score in a multicenter cohort study. Am J Respir Crit Care Med. 2013;187(8):832-9. https://doi.org/10. 1164/rccm.201210-1851OC

83. Kheterpal S, Han R, Tremper KK, Shanks A, Tait AR, O'Reilly $\mathrm{M}$, et al. Incidence and predictors of difficult and impossible mask ventilation. Anesthesiology. 2006;105(5):885-91. https://doi.org/ 10.1097/00000542-200611000-00007.

84. Kheterpal S, Martin L, Shanks AM, Tremper KK. Prediction and outcomes of impossible mask ventilation: a review of 50,000 anesthetics. Anesthesiology. 2009;110(4):891-7. https://doi.org/10. 1097/ALN.0b013e31819b5b87.
85. Saito T, Liu W, Chew ST, Ti LK. Incidence of and risk factors for difficult ventilation via a supraglottic airway device in a population of 14,480 patients from South-East Asia. Anaesthesia. 2015;70(9):1079-83. https://doi.org/10.1111/anae.13153.

86. Saito T, Chew ST, Liu WL, Thinn KK, Asai T, Ti LK. A proposal for a new scoring system to predict difficult ventilation through a supraglottic airway. Br J Anaesth. 2016;117(Suppl 1):i83-i6. https://doi.org/10.1093/bja/aew191.

87. Lundstrom LH, Rosenstock CV, Wetterslev J, Norskov AK. The DIFFMASK score for predicting difficult facemask ventilation: a cohort study of 46,804 patients. Anaesthesia. 2019;74(10):126776. https://doi.org/10.1111/anae.14701.

88. Semler MW, Janz DR, Russell DW, Casey JD, Lentz RJ, Zouk AN, et al. A multicenter, randomized trial of ramped position vs sniffing position during endotracheal intubation of critically ill adults. Chest. 2017;152(4):712-22. https://doi.org/10.1016/j. chest.2017.03.061.

89. Turner JS, Ellender TJ, Okonkwo ER, Stepsis TM, Stevens AC, Sembroski EG, et al. Feasibility of upright patient positioning and intubation success rates at two academic EDs. Am J Emerg Med. 2017;35(7):986-92. https://doi.org/10.1016/j.ajem.2017.02.011.

90. Khandelwal N, Khorsand S, Mitchell SH, Joffe AM. Headelevated patient positioning decreases complications of emergent tracheal intubation in the ward and intensive care unit. Anesth Analg. 2016;122(4):1101-7. https://doi.org/10.1213/ANE. 0000000000001184 .

91. Algie CM, Mahar RK, Tan HB, Wilson G, Mahar PD, Wasiak J. Effectiveness and risks of cricoid pressure during rapid sequence induction for endotracheal intubation. Cochrane Database Syst Rev. 2015;11:CD011656. https://doi.org/10.1002/14651858. CD011656.pub2.

92. Birenbaum A, Hajage D, Roche S, Ntouba A, Eurin M, Cuvillon $\mathrm{P}$, et al. Effect of cricoid pressure compared with a sham procedure in the rapid sequence induction of anesthesia: the IRIS randomized clinical trial. JAMA Surg. 2019;154(1):9-17. https://doi.org/10. 1001/jamasurg.2018.3577.

93. White L, Thang C, Hodsdon A, Melhuish T, Vlok R. Cricoid pressure during intubation: a systematic review and metaanalysis of randomised controlled trials. Heart Lung. 2020;49(2): 175-80. https://doi.org/10.1016/j.hrtlng.2019.10.001.

94. Haslam N, Parker L, Duggan JE. Effect of cricoid pressure on the view at laryngoscopy. Anaesthesia. 2005;60(1):41-7. https://doi. org/10.1111/j.1365-2044.2004.04010.x.

95. Olsen JC, Gurr DE, Hughes M. Video analysis of emergency medicine residents performing rapid-sequence intubations. $\mathrm{J}$ Emerg Med. 2000;18(4):469-72. https://doi.org/10.1016/s07364679(00)00168-2.

96. Kruisselbrink R, Gharapetian A, Chaparro LE, Ami N, Richler D, Chan VWS, et al. Diagnostic accuracy of point-of-care gastric ultrasound. Anesth Analg. 2019;128(1):89-95. https://doi.org/10. 1213/ANE.0000000000003372.

97. Van de Putte P, Perlas A. Ultrasound assessment of gastric content and volume. Br J Anaesth. 2014;113(1):12-22. https://doi.org/10. 1093/bja/aeu151.

98. Taboada M, Doldan P, Calvo A, Almeida X, Ferreiroa E, Baluja $\mathrm{A}$, et al. Comparison of tracheal intubation conditions in operating room and intensive care unit: a prospective, observational study. Anesthesiology. 2018;129(2):321-8. https://doi.org/10.1097/ ALN.0000000000002269.

99. Mosier JM, Malo J, Sakles JC, Hypes CD, Natt B, Snyder L, et al. The impact of a comprehensive airway management training program for pulmonary and critical care medicine fellows. A threeyear experience. Ann Am Thorac Soc. 2015;12(4):539-48. https:// doi.org/10.1513/AnnalsATS.201501-023OC.

100. Sakles JC, Augustinovich CC, Patanwala AE, Pacheco GS, Mosier JM. Improvement in the safety of rapid sequence 
intubation in the emergency department with the use of an airway continuous quality improvement program. West J Emerg Med. 2019;20(4):610-8. https://doi.org/10.5811/westjem.2019.4. 42343.

101.• Taboada M, Soto-Jove R, Miron P, Martinez S, Rey R, Ferreiroa $\mathrm{E}$, et al. Evaluation of the laryngoscopy view using the modified Cormack-Lehane scale during tracheal intubation in an intensive care unit. A prospective observational study. Rev Esp Anestesiol Reanim. 2019;66(5):250-8. https://doi.org/10.1016/j.redar.2019. 01.004 This article establishes that critically ill patients intubated in the ICU have worse outcomes compared to the same patients intubated by the same operators in the operating room.

102. Brown C III, Kaji A, Fantegrossi A, Carlson JN, April M, Kilgo R, et al. Video vs. augmented direct laryngoscopy in adult emergency department tracheal intubations: a National Emergency Airway Registry (NEAR) Study. Acad Emerg Med. 2019; in Press.

103. Driver BE, Prekker ME, Klein LR, Reardon RF, Miner JR, Fagerstrom ET, et al. Effect of use of a bougie vs endotracheal tube and stylet on first-attempt intubation success among patients with difficult airways undergoing emergency intubation: a randomized clinical trial. JAMA. 2018;319(21):2179-89. https:// doi.org/10.1001/jama.2018.6496.

104. Thomsen JLD, Norskov AK, Rosenstock CV. Supraglottic airway devices in difficult airway management: a retrospective cohort study of 658,104 general anaesthetics registered in the Danish Anaesthesia Database. Anaesthesia. 2019;74(2):151-7. https:// doi.org/10.1111/anae.14443.
105. Gaeckle NT, Lee J, Park Y, Kreykes G, Evans MD, Hogan CJ Jr. Aerosol generation from the respiratory tract with various modes of oxygen delivery. Am J Respir Crit Care Med. 2020;202(8): 1115-24. https://doi.org/10.1164/rccm.202006-2309OC.

106. Miller DC, Beamer P, Billheimer D, Subbian V, Sorooshian A, Campbell BS, et al. Aerosol risk with noninvasive respiratory support in patients with COVID-19. J Am Coll Emerg Physicians Open. 2020;1:521-6. https://doi.org/10.1002/emp2. 12152.

107. Lim ZJ, Ponnapa Reddy M, Karalapillai D, Shekar K, Subramaniam A. Impact of an aerosol box on time to tracheal intubation: systematic review and meta-analysis. $\mathrm{Br} \mathrm{J}$ Anaesth. 2021;126(3):e122-e5. https://doi.org/10.1016/j.bja. 2020.11.036.

108. Simpson JP, Wong DN, Verco L, Carter R, Dzidowski M, Chan PY. Measurement of airborne particle exposure during simulated tracheal intubation using various proposed aerosol containment devices during the COVID-19 pandemic. Anaesthesia. 2020;75(12):1587-95. https://doi.org/10.1111/anae.15188.

109. Sorbello M, Rosenblatt W, Hofmeyr R, Greif R, Urdaneta F. Aerosol boxes and barrier enclosures for airway management in COVID-19 patients: a scoping review and narrative synthesis. Br J Anaesth. 2020;125(6):880-94. https://doi.org/10.1016/j.bja.2020. 08.038 .

Publisher's Note Springer Nature remains neutral with regard to jurisdictional claims in published maps and institutional affiliations. 